\title{
Controversies in Clinical Trials of Cancer Vaccines for Glioblastoma
}

\author{
Mizuhiko Terasaki ${ }^{*}$, Kenta Murotani' ${ }^{2}$, Yoshitaka Narita ${ }^{3}$, Ryo Nishikawa ${ }^{4}$, Tetsuro Sasada ${ }^{5}$, Akira Yamada ${ }^{5,6}$ Kyogo Itoh ${ }^{5}$ and Motohiro \\ Morioka $^{1}$ \\ ${ }^{1}$ Department of Neurosurgery, Kurume University School of Medicine, Fukuoka \\ ${ }^{2}$ Translational Research Informatics Centre, Foundation of Biomedical Research and Innovation, Kobe \\ ${ }^{3}$ Neurosurgery Division, National Cancer Centre Hospital, Tokyo \\ ${ }^{4}$ Department of Neurosurgery, Saitama Medical University International Medical Centre, Saitama \\ ${ }^{5}$ Department of Immunology, Kurume University School of Medicine, Fukuoka \\ ${ }^{6}$ Research Centre for Innovative Cancer Therapy, Fukuoka, Japan
}

Keywords: Glioblastoma; Clinical trial; Tumour progression; Best recommended treatment

Glioblastoma multiforme (GBM), the most common primary brain tumour, continues to have a dismal prognosis. The standard initial treatment for GBM is surgical resection along with postoperative adjuvant therapy, including temozolomide, concomitant with 60 Gy of radiation therapy (RT) [1]. However, most patients eventually relapse and long-term survival remains elusive [2,3]. Thus, novel therapeutic modalities for GBM are being explored, and different types of immune-mediated approaches have been preclinically and clinically evaluated in phase I and II trials [4]. However, these GBM clinical trials face significant limitations in terms of their assessment of tumour progression and protocol setting. A critical and comprehensive review of how GBM trials should be conducted is required with a focus on how progression can be defined and clinical benefits can be evaluated following the administration of cancer vaccines.

\section{Limitations of the Conventional Tumour Progression Criteria}

In current clinical trials of therapies for solid Tumours, cessation of treatment is recommended once "progressive disease" (PD) is detected according to the $\mathrm{WHO}$ or response evaluation criteria in solid Tumours (RECIST) criteria. In the WHO criteria, PD is defined as at least a $25 \%$ increase in the sum of the products of the two largest perpendicular diameters (SPD) compared with nadir and/or unequivocal progression of non-index lesions and/or the appearance of new lesions [5]. In the RECIST criteria, a 20\% increase is defined as PD [6]. Criteria developed by Macdonald and colleagues in 1990 have also been used for assessing the anti-Tumour responses of gliomas [7]. These criteria are based on the two-dimensional WHO response criteria and mark the transition from a subjective interpretation of clinical and radiologic changes to a more objective evaluation. Other factors, such as the use of steroids and changes in neurologic status, are also included in the response assessment. Although they are widely accepted, a number of groups have reported a few limitations of these criteria [8-10]. Clinical evidences indicate that the traditional Macdonald's criteria may not be sufficient for completely characterizing responses in the new era of targeted therapies. Thus, ideal progression criteria that can comprehensively describe all patterns of anti-Tumour responses to cancer vaccines for gliomas remain to be developed.

New systematic criteria designated "immune-related response criteria" for describing additional response patterns observed with immunotherapies that cannot be assessed by the traditional RECIST or WHO criteria have recently been defined [11]. In these new criteria, progression is defined as $\geq 25 \%$ increase in Tumour burden compared with nadir at two consecutive time points at least 4 weeks apart in the absence of rapid clinical deterioration. However, these novel criteria may also be of limited value for assessing the anti-Tumour responses of gliomas, as explained below.

\section{Tumour Size Threshold for Defining PD}

Tumours with enhancement are defined as PD when the changes in the enhancing areas reach $25 \%$ according to Macdonald's criteria. However, whether it is appropriate to define $a \geq 25 \%$ increase in Tumour size as "PD" remains unknown. In fact, this issue was raised by our retrospective analysis of the personalized peptide ITK-1 vaccine trial for recurrent GBM, where a 54\% increase according to the WHO criteria or a $43 \%$ increase according to the RECIST criteria was predictive of a high mortality with a sensitivity of $69 \%$ (95\% confidence interval: $42 \%-87 \%$ ) and $85 \%$ (58\%-96\%), respectively (Figures $1 \mathrm{~A}$ and 1B). Our experience suggests that the Tumour size threshold for defining PD when evaluating the efficacy of cancer vaccines remains to be carefully determined.

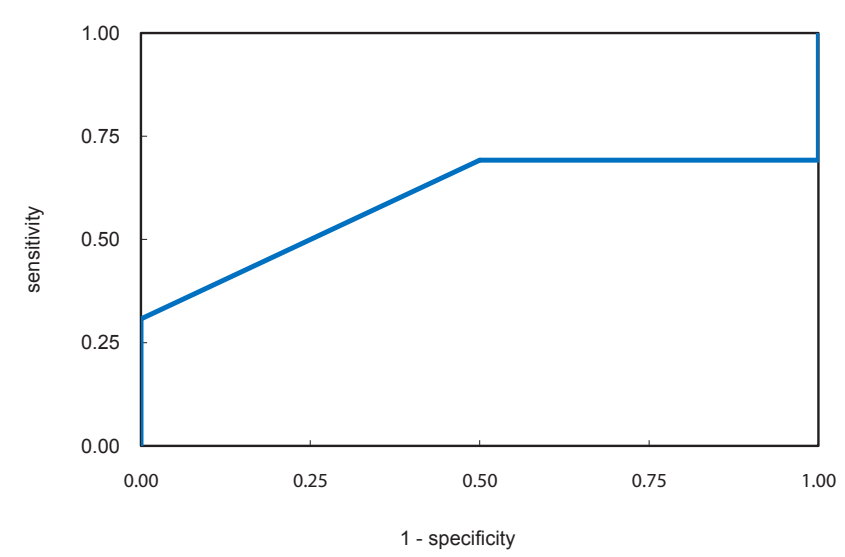

Figure 1a: ROC curve of increasing rate of tumor burden predicting mortality at progression according to the WHO criteria. The area under the ROC curve was $0.69(95 \% \mathrm{Cl}: 0.43,0.95)$. Increase in the SPD of at least $54 \%$ is predictive of mortality at progression with a sensitivity of $67 \%(42 \%, 87 \%)$ and a specificity of $50 \%(9 \%, 91 \%)$.

*Corresponding author: Mizuhiko Terasaki, Department of Neurosurgery, Kurume University School of Medicine, 67 Asahi-machi, Kurume, Fukuoka 830-0011, Japan, Tel: +81-942-35-3311; Fax: 81-942-38-8179; E-mail: jintara@med.kurume-u.ac.jp

Received January 16, 2013; Accepted January 29, 2013; Published January 31, 2013

Citation: Terasaki M, Murotani K, Narita Y, Nishikawa R, Sasada T, et al. (2013) Controversies in Clinical Trials of Cancer Vaccines for Glioblastoma. J Vaccines Vaccin 4: 171. doi:10.4172/2157-7560.1000171

Copyright: @ 2013 Terasaki M, et al. This is an open-access article distributed under the terms of the Creative Commons Attribution License, which permits unrestricted use, distribution, and reproduction in any medium, provided the original author and source are credited. 


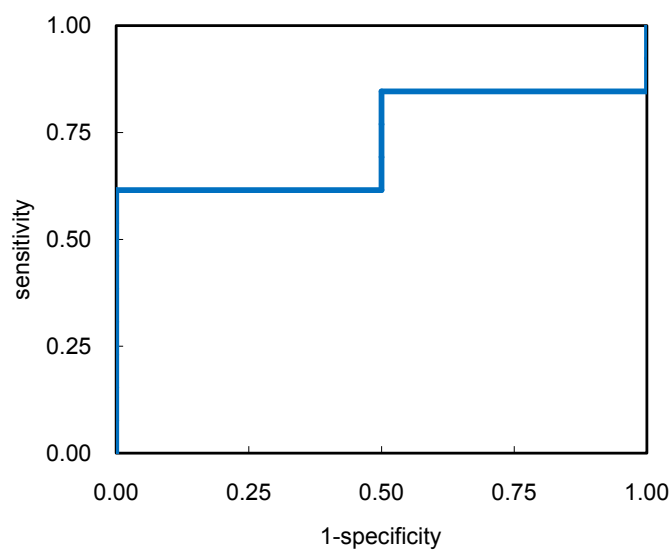

Figure 1b: ROC curve of increasing rate of tumor burden predicting mortality at progression according to the RECIST criteria. The area under the ROC curve was $0.73(95 \% \mathrm{Cl}: 0.42,1.00)$. Increases in the largest perpendicular diameters of at least $43 \%$ are predictive of mortality at progression with a sensitivity of $85 \%(58 \%, 96 \%)$ and a specificity of $50 \%(9 \%, 91 \%)$.
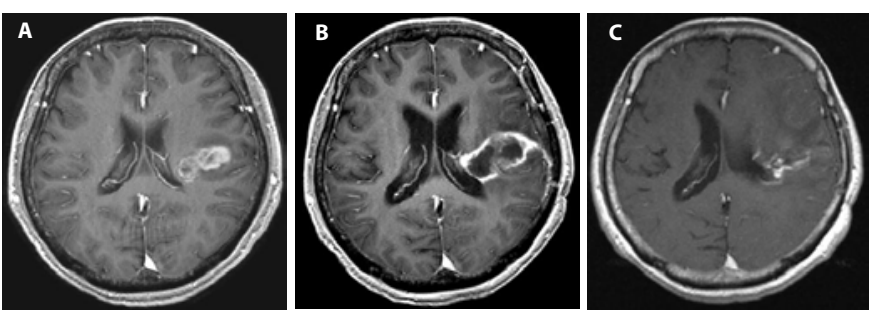

Figure 2: Example of pseudoprogression after vaccination.

(A) T1-weighted contrast-enhanced magnetic resonance image (MRI) from a 59-year-old patient with biopsy-proven glioblastoma before vaccination.

(B) Eight weeks after vaccination, a significant increase in contrast enhancement was shown.

(C) On a follow-up MRI 24 weeks later, a significant reduction was observed in the enhancing lesions.

\section{Controversy Evaluating Enhancing Lesions}

Tumour enhancement has been assessed based on the extent of Tumour-occupying lesions when evaluating Tumour size. However, considering that clinical trials of cancer vaccines for gliomas have been attempted in patients at various stages and with various conditions of disease, tumour enhancement may be influenced by not only cancer cell occupation but also by several other factors, including postsurgical changes, disruption of the blood-brain barrier, inflammation, radiation necrosis, and use of corticosteroids [12-17]. These changes in enhancing areas are not always directly correlated with those of Tumour-occupying lesions. Stable disease (SD) in the enhancing areas might be considered an indicator of significant therapeutic effects in cancer vaccine trials [18]. For example, it is possible that enhancement within Tumours may be, at least in part, attributed to autoimmune responses and/or brain inflammation caused by systemic immunization [4].

\section{Tumour Regression after Apparent PD}

Clinical studies of cancer vaccines have in certain cases shown that initial induction of SD or PD is followed by subsequent Tumour regression, raising concerns about evaluation of anti-Tumour responses using the WHO or RECIST criteria $[11,19]$. Such radiological increases in Tumour volumes that precede beneficial clinical responses in patients administered cancer vaccines may be attributed to either continued Tumour growth until sufficient anti-Tumour activity develops, or to transient infiltration of immune cells. In addition, transient increases in enhancement without actual Tumour progression, known as "pseudo progression", have been reported in multiple studies of immunotherapeutic agents [20,21]. For example, in our previous cancer vaccine trial, significant clinical effects after 12 weeks, and in certain cases even after 24 weeks, were observed in a subset of patients with apparent $\mathrm{PD}$ according to the classical progression criteria (Figures 2A, 2B and 2C) [22]. Considering the fact that follow-up observations cannot be mandated in patients with PD in most clinical trial protocols, the actual number of patients with beneficial clinical responses after PD may be underestimated. This could limit the value of progression-free survival as a primary end point in cancer vaccine trials.

Collectively, clinical development of cancer vaccines has been hampered by the absence of ideal progression criteria that can comprehensively describe all patterns of anti-Tumour response. Establishment of specific guidelines for classifying Tumour progression to evaluate anti-Tumour activities remains an urgent issue in relation to cancer vaccine trials for gliomas.

\section{Overall Survival as a Primary Endpoint in Cancer Vaccine Trials for Gliomas}

Since the numbers of patients with high-grade glioma, particularly GBM, are limited, it would be quite difficult to conduct large-scale immunotherapy trials for this disease [4,12]. The number of patients receiving treatments is relatively small in cancer vaccine trials, and the evaluation criteria vary depending on the trial [22-42]. Such large variations in immune-based therapeutic approaches for GBM make direct comparison difficult. Given this situation, the immunotherapy field needs to urgently address what clinical benefits can be detected in such small-scale, limited clinical trials, and how these can be evaluated. One possibility would be to concentrate on evaluating overall survival (OS). Because of a lack of effective treatments for refractory GBM, the effect of a particular treatment on OS may not be influenced by subsequent salvage treatments.

\section{Combination with the Best Recommended Treatment}

A novel hypothetical consideration may be combination therapy with additional agents in GBM vaccine trials, which may enhance the clinical effects of cancer vaccines. Recently, concomitant treatments including RT, chemotherapies, and targeted therapies, have been reported to enhance the therapeutic effects of cancer vaccines through multiple immune-related mechanisms (i.e., activation of antigenpresenting cells or cytotoxic T cells and removal of suppressor cells) $[43,44]$. Several clinical studies have shown that chemotherapies combined with cancer vaccines can have a synergistic effect [44]. Synergistic effects of salvage chemotherapies after therapeutic cancer vaccination were also reported to improve patient survival in two clinical studies of GBM and small cell lung cancer [45,46]. Sampson et al. [47] reported that cancer vaccination after concomitant RT and temozolomide provided a survival advantage of 9 months compared with control patients in a phase II multicenter trial in patients with newly diagnosed GBM. These clinical studies illustrate that cancer vaccines combined with other treatment modalities may provide a valid therapeutic option for GBM. Therefore, the best recommended treatment (BRT) could be combined with chemotherapies and/ or radiotherapies but not with best supportive care (BSC) in clinical trials of cancer vaccines for GBM. This will facilitate the occurrence 
of synergistic effects, although the appropriate doses and schedules for optimal synergy between chemotherapies and cancer vaccines remain to be determined.

Considering the disease rarity and the limited survival benefit derived from cancer vaccines for GBM, the employment of BRT (but not of BSC), which could synergistically enhance the clinical effects of the cancer vaccines, would be a breakthrough for accelerated development of cancer vaccines. The FDA also supports this type of combination therapy in their guidelines for the development of therapeutic cancer vaccines [48].

\section{Disclosure Statement}

No part of this report has been previously presented elsewhere.

Terasaki received a research grant from the Suzuken Memorial Foundation, Itoh have stock ownership in the Green Peptide Co., Nishikawa had honoraria from the MSD Co, Ltd.

\section{Conflict of Interest}

The authors report no potential conflict of interest except for Itoh.

\section{References}

1. Stupp R, Hegi ME, Mason WP, Van den Bent MJ, Taphoorn MJ, et al. (2009) Effects of radiotherapy with concomitant and adjuvant temozolomide versus radiotherapy alone on survival in glioblastoma in a randomised phase III study: 5-year analysis of the EORTC-NCIC trial. Lancet Oncol 10: 459-466.

2. Louis DN, Ohgaki H, Wiestler OD, Cavenee WK, Burger PC, et al. (2007) The 2007 WHO classification of tumours of the central nervous system. Acta Neuropathol 114: 97-109.

3. Stupp R, Hegi ME, Van den Bent MJ, Mason WP, Weller M, et al. (2006) Changing paradigms--an update on the multidisciplinary management of malignant glioma. Oncologist 11: 165-180.

4. Lowenstein PR (2010) Cancer vaccines in glioma: how to balance the challenges of small trials, efficiency, and potential adverse events. J Clin Oncol 28: $4670-4673$

5. Miller AB, Hoogstraten B, Staquet M, Winkler A (1981) Reporting results of cancer treatment. Cancer 47: 207-214.

6. James K, Eisenhauer E, Christian M, Terenziani M, Vena D, et al. (1999) Measuring response in solid tumours: unidimensional versus bidimensional measurement. J Natl Cancer Inst 91: 523-528.

7. Macdonald DR, Cascino TL, Schold SC Jr, Cairncross JG (1990) Response criteria for phase II studies of supratentorial malignant glioma. J Clin Oncol 8: 1277-1280.

8. Brada M, Yung WK (2000) Clinical trial end points in malignant glioma: need for effective trial design strategy. Semin Oncol 27: 11-19.

9. Galanis E, Buckner JC, Maurer MJ, Sykora R, Castillo R, et al. (2006) Validation of neuroradiologic response assessment in gliomas: measurement by RECIST, two-dimensional, computer-assisted tumour area, and computer-assisted tumour volume methods. Neuro Oncol 8: 156-165.

10. Van den Bent MJ, Vogelbaum MA, Wen PY, Macdonald DR, Chang SM (2009) End point assessment in gliomas: novel treatments limit usefulness of classical Macdonald's Criteria. J Clin Oncol 27: 2905-2908.

11. Wolchok JD, Hoos A, O'Day S, Weber JS, Hamid O, et al. (2009) Guidelines for the evaluation of immune therapy activity in solid tumours: immune-related response criteria. Clin Cancer Res 15: 7412-7420.

12. Wheeler CJ, Black KL (2011) Vaccines for glioblastoma and high-grade glioma Expert Rev Vaccines 10: 875-886.

13. Cairncross JG, Macdonald DR, Pexman JH, Ives FJ (1988) Steroid-induced CT changes in patients with recurrent malignant glioma. Neurology 38: 724-726.

14. Finn MA, Blumenthal DT, Salzman KL, Jensen RL (2007) Transient posticta MRI changes in patients with brain tumours may mimic disease progression. Surg Neurol 67: 246-250.

15. Henegar MM, Moran CJ, Silbergeld DL (1996) Early postoperative magnetic resonance imaging following nonneoplastic cortical resection. J Neurosurg 84 174-179.

16. Taal W, Brandsma D, de Bruin HG, Bromberg JE, Swaak-Kragten AT, et al (2008) Incidence of early pseudo-progression in a cohort of malignant glioma patients treated with chemoirradiation with temozolomide. Cancer 113: 405 410

17. Watling CJ, Lee DH, Macdonald DR, Cairncross JG (1994) Corticosteroidinduced magnetic resonance imaging changes in patients with recurrent malignant glioma. J Clin Oncol 12:1886-1889.

18. Dougan M, Dranoff G (2009) Immune therapy for cancer. Annu Rev Immuno 27: 83-117.

19. Van Baren N, Bonnet MC, Dreno B, Khammari A, Dorval T, et al. (2005) Tumoural and immunologic response after vaccination of melanoma patients with an ALVAC virus encoding MAGE antigens recognized by T cells. J Clin Oncol 23: 9008-9021.

20. Parney IF, Kunwar S, McDermott M, Berger M, Prados M, et al. (2005) Neuroradiographic changes following convection-enhanced delivery of the recombinant cytotoxin interleukin 13-PE38QQR for recurrent malignant glioma. J Neurosurg 102: 267-275.

21. Smith MM, Thompson JE, Castillo M, Cush S, Mukherji SK, et al. (1996) MR of recurrent high-grade astrocytomas after intralesional immunotherapy. AJNR Am J Neuroradiol 17: 1065-1071.

22. Terasaki M, Shibui S, Narita Y, Fujimaki T, Aoki T, et al. (2011) Phase I trial of a personalized peptide vaccine for patients positive for human leukocyte antigen-A24 with recurrent or progressive glioblastoma multiforme. J Clin Oncol 29: 337-344.

23. Ahmed R, Zha XM, Green SH, Dailey ME (2006) Synaptic activity and F-actin coordinately regulate CaMKIlalpha localization to dendritic postsynaptic sites in developing hippocampal slices. Mol Cell Neurosci 31: 37-51.

24. Bao L, Dunham K, Stamer M, Mulieri KM, Lucas KG (2008) Expansion of cytomegalovirus pp65 and IE-1 specific cytotoxic $T$ lymphocytes for cytomegalovirus-specific immunotherapy following allogeneic stem cell transplantation. Biol Blood Marrow Transplant 14: 1156-1162.

25. Bao L, Sun Q, Lucas KG (2007) Rapid generation of CMV pp65-specific T cells for immunotherapy. J Immunother 30: 557-561.

26. Broder H, Anderson A, Kremen TJ, Odesa SK, Liau LM (2003) MART-1 adenovirus-transduced dendritic cell immunization in a murine model of metastatic central nervous system tumor. J Neurooncol 64: 21-30.

27. Choi BD, Archer GE, Mitchell DA, Heimberger AB, McLendon RE, et al. (2009) EGFRvIll-targeted vaccination therapy of malignant glioma. Brain Pathol 19 713-723.

28. De Vleeschouwer S, Fieuws S, Rutkowski S, Van Calenbergh F, Van Loon J, et al. (2008) Postoperative adjuvant dendritic cell-based immunotherapy in patients with relapsed glioblastoma multiforme. Clin Cancer Res 14: 30983104.

29. Dillman RO, Duma CM, Schiltz PM, DePriest C, Ellis RA, et al. (2004) Intracavitary placement of autologous lymphokine-activated killer (LAK) cells after resection of recurrent glioblastoma. J Immunother 27: 398-404.

30. Heimberger AB, Crotty LE, Archer GE, Mc Lendon RE, Friedman A, et al. (2000) Bone marrow-derived dendritic cells pulsed with tumour homogenate induce immunity against syngeneic intracerebral glioma. J Neuroimmunol 103:16-25.

31. Heimberger AB, Sampson JH (2009) The PEPvIII-KLH (CDX-110) vaccine in glioblastoma multiforme patients. Expert Opin Biol Ther 9: 1087-1098.

32. Heimberger AB, Sun W, Hussain SF, Dey M, Crutcher L, et al. (2008) Immunological responses in a patient with glioblastoma multiforme treated with sequential courses of temozolomide and immunotherapy: case study. Neuro Oncol 10: 98-103.

33. Kahlon KS, Brown C, Cooper LJ, Raubitschek A, Forman SJ, et al. (2004 Specific recognition and killing of glioblastoma multiforme by interleukin 13-zetakine redirected cytolytic T cells. Cancer Res 64: 9160-9166.

34. Liau LM, Jensen ER, Kremen TJ, Odesa SK, Sykes SN, et al. (2002) Tumo immunity within the central nervous system stimulated by recombinant Listeria monocytogenes vaccination. Cancer Res 62: 2287-2293.

35. Liau LM, Prins RM, Kiertscher SM, Odesa SK, Kremen TJ, et al. (2005) Dendritic cell vaccination in glioblastoma patients induces systemic and 
Citation: Terasaki M, Murotani K, Narita Y, Nishikawa R, Sasada T, et al. (2013) Controversies in Clinical Trials of Cancer Vaccines for Glioblastoma. J Vaccines Vaccin 4: 171. doi:10.4172/2157-7560.1000171

intracranial T-cell responses modulated by the local central nervous system tumor microenvironment. Clin Cancer Res 11: 5515-5525.

36. Okada H, Lieberman FS, Walter KA, Lunsford LD, Kondziolka DS, et al. (2007) Autologous glioma cell vaccine admixed with interleukin-4 gene transfected fibroblasts in the treatment of patients with malignant gliomas. J Transl Med 5: 67 .

37. Schmittling RJ, Archer GE, Mitchell DA, Heimberger A, Pegram C, et al (2008) Detection of humoral response in patients with glioblastoma receiving EGFRvIII-KLH vaccines. J Immunol Methods 339: 74-81.

38. Sloan AE, Dansey R, Zamorano L, Barger G, Hamm C, et al. (2000) Adoptive immunotherapy in patients with recurrent malignant glioma: preliminary results of using autologous whole-tumor vaccine plus granulocyte-macrophage colonystimulating factor and adoptive transfer of anti-CD3-activated lymphocytes. Neurosurg Focus 9: e9.

39. Wheeler CJ, Black KL, Liu G, Mazer M, Zhang XX, et al. (2008) Vaccination elicits correlated immune and clinical responses in glioblastoma multiforme patients. Cancer Res 68: 5955-5964.

40. Yajima N, Yamanaka R, Mine T, Tsuchiya N, Homma J, et al. (2005) Immunologic evaluation of personalized peptide vaccination for patients with advanced malignant glioma. Clin Cancer Res 11: 5900-5911.

41. Yu JS, Liu G, Ying H, Yong WH, Black KL, et al. (2004) Vaccination with tumo lysate-pulsed dendritic cells elicits antigen-specific, cytotoxic T-cells in patients with malignant glioma. Cancer Res 64: 4973-4979.
42. Yu JS, Wheeler CJ, Zeltzer PM, Ying H, Finger DN, et al. (2001) Vaccination of malignant glioma patients with peptide-pulsed dendritic cells elicits systemic cytotoxicity and intracranial T-cell infiltration. Cancer Res 61: 842-847.

43. Zitvogel L, Tesniere A, Apetoh L, Ghiringhelli F, Kroemer G (2008) [Immunological aspects of anticancer chemotherapy]. Bull Acad Natl Med 192: 1469-1487.

44. Zitvogel L, Apetoh L, Ghiringhelli F, Kroemer G (2008) Immunological aspects of cancer chemotherapy. Nat Rev Immunol 8: 59-73.

45. Antonia SJ, Mirza N, Fricke I, Chiappori A, Thompson P, et al. (2006) Combination of p53 cancer vaccine with chemotherapy in patients with extensive stage small cell lung cancer. Clin Cancer Res 12: 878-887.

46. Wheeler CJ, Das A, Liu G, Yu JS, Black KL (2004) Clinical responsiveness of glioblastoma multiforme to chemotherapy after vaccination. Clin Cancer Res 10: $5316-5326$

47. Sampson JH, Heimberger AB, Archer GE, Aldape KD, Friedman AH, et al (2010) Immunologic escape after prolonged progression-free survival with epidermal growth factor receptor variant III peptide vaccination in patients with newly diagnosed glioblastoma. J Clin Oncol 28: 4722-4729.

48. (2009) Draft Guidance for Industry: Clinical Considerations for Therapeutic Cancer Vaccines, US Department of Health and Human Services, Food and Drug Administration, Center for Biologics Evaluation and Research. 